\title{
Isolation and molecular characterization of bacteria from the gut of Eisenia fetida for biodegradation of 4,4 DDT
}

\author{
Reagan Mudziwapasi ${ }^{1}$, Sibonani S. Mlambo ${ }^{1}$, Nomathemba L. Chigu ${ }^{1}$, Pardon K. Kuipa ${ }^{2}$, Walter T. Sanyika ${ }^{1}$ \\ ${ }^{1}$ Biotechnology Department, School of Agricultural Sciences and Technology, Chinhoyi University of Technology, Chinhoyi, Zimbabwe. \\ ${ }^{2}$ Fuels and Energy Department, School of Engineering Sciences and Technology, Chinhoyi University of Technology, Chinhoyi, Zimbabwe.
}

\begin{tabular}{l}
\hline ARTICLE INFO \\
\hline Article history: \\
Received on: 06/04/2016 \\
Revised on: $26 / 05 / 2016$ \\
Accepted on: 03/07/2016 \\
Available online: 19/09/2016 \\
\hline Key words: \\
Biodegradation, earthworm \\
gut, Eisenia fetida, 4,4 DDT.
\end{tabular}

\begin{abstract}
There is a growing interest in the bio-application of microorganisms from the gut of earthworms on the biotransformation of persistent and toxic pollutants during vermifiltration. Earthworms harbor beneficial microbes in their gut which symbiotically aid in biodegradation of pollutants in their drilosphere. Dichlorodiphenyltrichloroethane (DDT) is an example of polychlorinated hydrocarbons and metabolites thereof that are persistent in the environment and are toxic to humans and animals. This study aimed at isolating and identifying 4,4 DDT degrading microorganisms in the gut of Eisenia fetida acclimatized to sewage. Five pure isolates obtained from gut contents were cultured in MSM supplemented with $15 \mathrm{mgL}^{-1}$ DDT followed by glucose yeast extract agar sprayed with $1 \% 4,4$ DDT in ether (v/v). Two pure isolates positive for 4,4 DDT biodegradation were inoculated on MSM containing $15 \mathrm{mgL}-1$ 4,4 DDT. The resulting metabolites were identified using Gas Chromatography. The positive isolates were identified using 16S rRNA gene analysis as belonging to the Rhodococcus genus and the Bacillus genus, exhibiting $88.36 \%$ and $85.22 \% 4.4$ DDT degradation respectively. The study demonstrated DDT-degradation by bacteria from the gut of E. fetida. These findings can be useful in optimization of vermifilters for biodegradation of DDT and other xenobiotics.
\end{abstract}

\section{INTRODUCTION}

Earthworms harbor beneficial microbes in their gut which symbiotically aid in biodegradation of pollutants in their drilosphere. Therefore there is a growing interest in the bioapplication of microorganisms from the gut of earthworms on the bio-transformation of persistent and toxic pollutants during vermifiltration. Using microorganisms to biodegrade toxic and persistent compounds in the environment is now widely recognized as an emerging effective, economic [1] and environmentally sustainable technology [2]. Polychlorinated hydrocarbons such as DDT are mutagenic and toxic to humans and animals. They can be present in soil and sediments where they exist for very long periods of time since their biodegradation is very slow $[2,3,4,5]$. Only $1 \%$ of the DDT

\footnotetext{
* Corresponding Author

Biotechnology Department, School of Agricultural Sciences and Technology, Chinhoyi University of Technology, P. bag 7724, Chinhoyi, Zimbabwe.Email: reaganmudziwapasi@gmail.com
}

used reaches the targeted pests while the rest goes into soil and water [6]. DDT and its residues (DDD (1,1-dichloro-2,2-bis-(4chlorophenyl)ethane, DDE (1,1-dichloro-2,2-bis-(4-chlorophenyl) ethylene) and DDA (bis(4-chlorophenyl)-acetic acid) are persistent in the environment $[7,8]$. DDT has been used since the 1940s for control of agricultural pests although it is now mainly used for mosquito control in some developing countries including Zimbabwe due to its high excito-repellency factor and low cost [1, 9, 10]. The two isomers of DDT are 2,4 DDT $(2,4$ 'dichlorodiphenyltrichloroethane) and 4,4 DDT $(4,4$ dichlorodiphenyltrichloroethane), of which 4,4 DDT is predominant. DDT enters the municipal wastewater systems mainly through use in pest control and has been detected in treated wastewater [11, 12] sewage, lakes and in rivers [7]. Currently wastewater treatment plants in Zimbabwe are not optimized for removal of xenobiotics such as persistent organic pollutants, pharmaceuticals and a wide spectrum of endocrine disrupting chemicals. Photoremediation, hydrodechlorination, electrolysis and reductive dechlorination using metals are some of the modern techniques that have been applied to degrade DDT under mild conditions but are too expensive for low income nations [13]. 
Vermifiltration, which is the use of earthworm-packed bioreactors for wastewater treatment, is gaining wide acceptance globally as an environmentally friendly and sustainable method of wastewater treatment. The earthworm Eisenia fetida has been successfully used to treat wastewater in vermifiltration based systems [14, 15] and in bioremediation of contaminated sites [14]. It significantly increases rate of decomposition of organic matter while rapidly increasing its own weight making it a model species for vermiprocesses [16]. Earthworms ingest waste and act in symbiosis with their gut microbes to detoxify waste or effluent [7, 17]. Therefore it is of interest to researchers to characterize the pollutant-degrading capabilities of these gut microbes. Some key resident microorganisms that have been identified as abundant in the gut of Eisenia fetida include some from the genera Tsukamurella, Klebsiella, Bacillus, Streptomyces, Microbacterium, Agromyces, Rhodococcus and Pseudomonas [16]. Microbial degradation as a method of targeting environmental DDT residues is gaining popularity due to the low degradability of DDT and its residues under in-situ conditions [8, 18]. Microbes with DDT-degrading ability have been isolated from soil [8, 19, 20, 21], mouse intestine, rat faeces, activated sludge, raw sewage, sewage sludge and genetically engineered microbes [1, 7]. This study was aimed at screening, isolating and identifying bacteria in the earthworm gut capable of degrading 4,4 DDT, for application in bioreactor design for wastewater treatment systems.

\section{MATERIALS AND METHODS}

\subsection{Isolation of microorganisms from earthworm gut}

Earthworms (Red worm: Eisenia fetida) were collected from the vermifiltration-based bioreactor after a 20-day period of acclimatization to raw sewage. The earthworms were washed in sterile distilled water, surface sterilized with $20 \%$ ethanol and dissected to expose the gut contents. The gut contents were suspended in $1 \mathrm{ml}$ sterile distilled water, and vortexed for 30 seconds.

\subsection{Enrichment culture of 4,4 DDT-degrading microbes}

Minimum salt media (MSM) with $15 \mathrm{mgL}^{-1}$ 4,4 DDT (Sigma Aldrich, Germany) was constituted to contain (per litre of distilled water): $\mathrm{Na}_{2} \mathrm{HPO}_{4} \cdot 2 \mathrm{H}_{2} \mathrm{O} \quad(2.67 \mathrm{~g}), \mathrm{KH}_{2} \mathrm{PO}_{4} \quad(1.4 \mathrm{~g})$, $\mathrm{MgSO}_{4} \cdot 7 \mathrm{H}_{2} \mathrm{O}(0.2 \mathrm{~g}),\left(\mathrm{NH}_{4}\right)_{2} \mathrm{SO}_{4}(0.5 \mathrm{~g})$ and $10 \mathrm{ml}$ of a solution of trace elements with the following composition per liter: $\mathrm{NaOH}$ (2g), $\mathrm{Na}_{2}$ EDTA. $2 \mathrm{H}_{2} \mathrm{O}$ (12g), $\mathrm{FeSO}_{4} \cdot 7 \mathrm{H}_{2} \mathrm{O}$ (2g), $\mathrm{CaCl}_{2}$ (1g), $\mathrm{Na}_{2} \mathrm{SO}_{4}(10 \mathrm{~g}), \mathrm{ZnSO}_{4}(0.4 \mathrm{~g}), \mathrm{MnSO}_{4} \cdot 4 \mathrm{H}_{2} \mathrm{O}(0.4 \mathrm{~g}), \mathrm{CuSO}_{4} .5 \mathrm{H}_{2} \mathrm{O}$ (0.1g), $\mathrm{Na}_{2} \mathrm{MoO}_{4} \cdot 2 \mathrm{H}_{2} \mathrm{O}(0.1 \mathrm{~g})$ and $98 \% \mathrm{H}_{2} \mathrm{SO}_{4}(0.5 \mathrm{ml})$.

Gut contents were inoculated in MSM containing 15 $\mathrm{mgL}^{-1} 4,4$ DDT using a sterile loop, and incubated at $30^{\circ} \mathrm{C}$ for 5 days with shaking at $100 \mathrm{rpm}$. Absorbance at $600 \mathrm{~nm}$ was measured periodically to track increase in optical density (OD).

\subsection{Screening for 4,4 DDT degrading microorganisms}

Loop-fulls of the cultures of gut contents in MSM containing $15 \mathrm{mgL}^{-1} 4,4$ DDT were streaked on nutrient agar and incubated at $30^{\circ} \mathrm{C}$ for 48 hours. The bacterial colonies that grew were purified on nutrient agar by picking individual distinct colonies and streaking on sterile nutrient agar plates. The pure colonies obtained on the nutrient agar were inoculated in nutrient broth and incubated at $30^{\circ} \mathrm{C}$ for $48 \mathrm{hrs}$.

\subsection{Ether spray method}

The pure cultures were streaked separately on glucose yeast extract agar and sprayed with 1\% 4,4 DDT in ether (v/v). The plates were incubated at $30{ }^{\circ} \mathrm{C}$ for 5 days. Colonies of 4,4 DDT-degrading bacteria were identified by formation of a distinct yellow color [8].

\subsection{Identification of 4,4 DDT degradation metabolites}

The isolates that gave a positive reaction for 4,4 DDT degradation following the ether spray method were inoculated in MSM containing $15 \mathrm{mgL}^{-1}$ 4,4 DDT. The isolates were incubated in the 4,4 DDT containing MSM at $30^{\circ} \mathrm{C}$ for 15 days with shaking at $100 \mathrm{rpm}$. 4,4 DDT and its degradation metabolites were identified and quantified using Gas chromatography on the Clarus 500 PE autosystem GC with built in autosampler. The injection volume was $2 \mu 1$.

\subsection{S rRNA gene analysis}

To extract DNA, $1.5 \mathrm{ml}$ of each liquid culture of the pure isolates in nutrient broth was centrifuged at $11000 \mathrm{rpm}$ for 3 minutes. The supernatant was discarded and the pellet was dissolved in $200 \mu \mathrm{l}$ of nuclease free water. The ZR Fungal/Bacterial DNA MiniPrep ${ }^{\mathrm{TM}}$ Kit (Inqaba Biotec, South Africa), was then used to extract DNA from the bacterial cultures following manufacturer's instructions. The DNA was eluted in $50 \mu 1$ of DNA elution buffer. The primers used in this study were 8F 5'- AGA GTT TGA TCC TGG CTC AG-3' forward primer and 1492R 5'- GGT TAC CTT GTT ACG ACT T -3' reverse primer (Bosshard et al., 2000). The 16S rRNA gene PCR was done following standard procedures. The master mix contained $8 \mu \mathrm{l}$ of PCR water, $10 \mu \mathrm{l}$ of Phusion flash master mix, $0.5 \mu \mathrm{l}$ each of the $8 \mathrm{~F}$ and $1492 \mathrm{R}$ primer pair and $1 \mu \mathrm{l}$ of the DNA template. The PCR cycling conditions were one cycle of initial denaturation at $98^{\circ} \mathrm{C}$ for 10 seconds, 30 cycles of denaturation at $98^{\circ} \mathrm{C}$ for 1 second, annealing at $55^{\circ} \mathrm{C}$ for 5 seconds and extension at $72^{\circ} \mathrm{C}$ for 15 seconds followed by one cycle of final extension at $72^{\circ} \mathrm{C}$ for 1 minute.

The 16S rRNA gene PCR products were separated on $1 \%$ agarose gel. The gel was run at $100 \mathrm{~V}$ for 90 minutes. The gel was viewed and photographed under the INFINITY-ST5-1150/20M gel documentation system and the DNA bands were viewed and cut using the DR-89X dark reader trans-illuminator and gel cutting tips. The bands were sequenced at Inqaba Biotec South Africa using Sanger sequencing in particular the ABI V3.1 Big dye kit on the ABI 3500XL Genetic Analyser according to manufacturer's instructions.

The sequences were edited using BioEdit v 5.0.9 software and subsequently aligned using ClustalW multiple 
alignment. The consensus sequences were compared with sequences from GenBank using the Basic Local Alignment Search Tool (BLAST). The dendograms were constructed using the Neighbor Joining algorithm processed using MEGA 6 software with a 500 repetition bootstrap.

\section{RESULTS AND DISCUSSION}

There are several factors that will determine the occurrence of a microbial population within the gut of an earthworm. The enzymatic activity in earthworms is dependent on species, reproduction stage of earthworms and substrate media [22]. During passage through the earthworm gut some bacteria remain unaffected, others are activated while some are digested thereby reducing their populations [23].

Microbial composition in the earthworm's environment in a vermifilter can differ from that in earthworm casts due to competitive interactions between endosymbiotic bacteria residing in earthworm gut and ingested bacteria [24]. Physicochemical conditions in the earthworm gut and its anaerobic environment, the gut fluids' selective suppressive activity against specific groups of microorganisms also influence microbial populations. There is also lysis of some microbes by digestive enzyme secretions of the earthworm and the possible inhibitory effect from substances that are secreted by other bacteria $[17,24]$.

\subsection{Growth of microbes on MSM supplemented with 4,4 DDT}

The increase in OD (Fig. 1) corresponds with an increase in microbial growth over time, indicating proliferation of microbial cells capable of utilizing 4,4 DDT as a sole source of carbon.

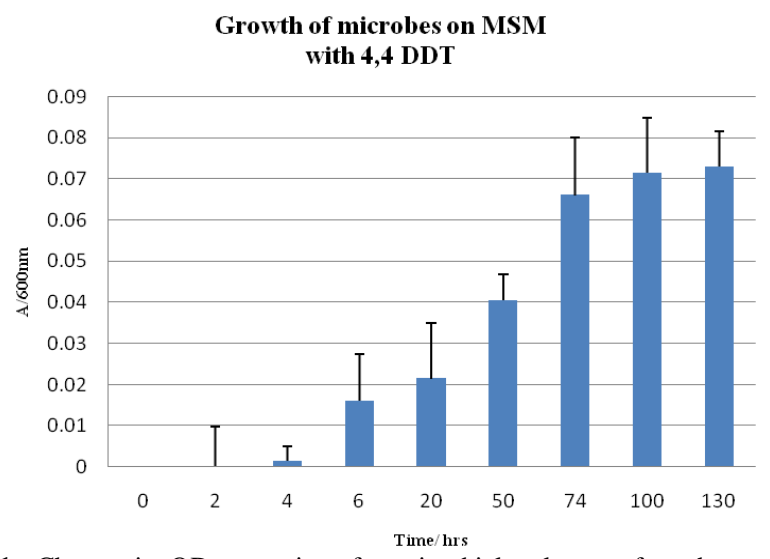

Fig. 1: Change in OD over time for microbial cultures of earthworm gut extracts grown in MSM supplemented with $15 \mathrm{mgL}^{-1}$ 4,4 DDT.

The lag phase lasted 4 hours, whereby bacteria adapted to growth conditions, synthesizing other molecules and maturing without dividing, at high substrate concentration. The log phase, which is characterized by high rates of cell division and decreasing substrate concentration, occurred between 4 and 130 hours. Fig. 1 shows that the microbes from the gut of E. fetida took a long time to reach stationary phase growing on DDT as the sole carbon source. The presence of additional carbon sources can shorten the time taken to reach maximum growth, as shown in a study where growth of $F$. oryzihabitants and $P$. aeruginosa grown on different carbon sources supplemented with $50 \mathrm{mgL}^{-1}$ DDT reached a maximum after 24 to 48 hours of incubation at $30^{\circ} \mathrm{C}$. The study achieved complete degradation of DDT at $15 \mathrm{mgL}^{-1}$ showing inhibitory effects at $50 \mathrm{mgL}^{-1}[25]$.

\subsection{DDT screening by ether spray method}

Five pure isolates designated isolate 1, 2, 3, 4 and 5 were obtained on MSM. Fig. 2 shows positive results for Isolates 3 and 5 and negative results for Isolates 1,2 and 4 after 5 days of incubation at $30^{\circ} \mathrm{C}$.

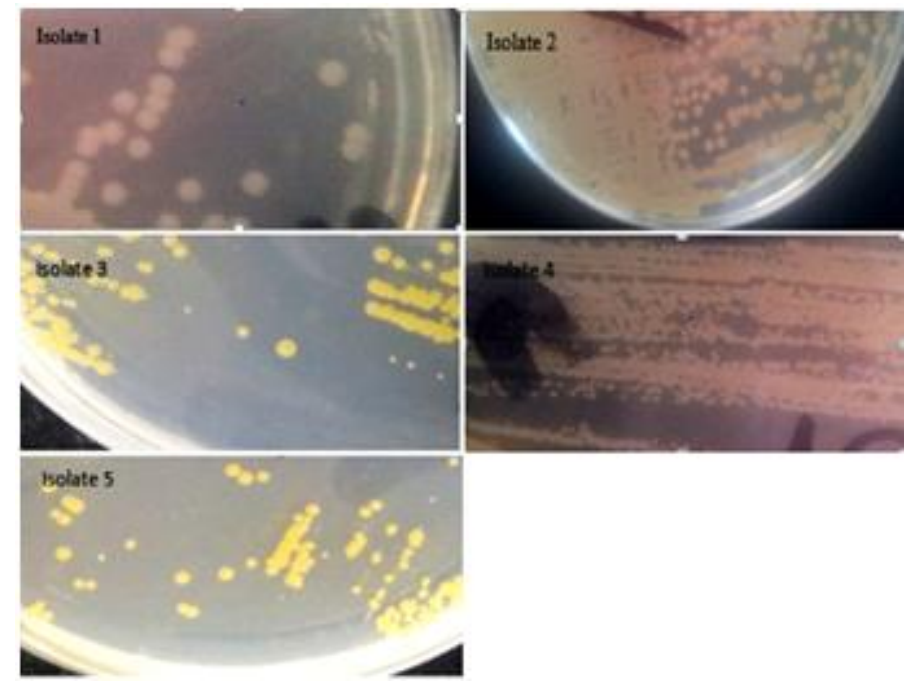

Fig. 2: Isolates growing on yeast extract agar with 1\% DDT.

The two isolates which gave a positive result for 4,4 DDT degradation were identified as belonging to the Rhodococcus genus (Isolate 5) and Bacillus genus (Isolate 3). Bacillus sp. with DDT degrading ability has also been isolated from soil [9, 26]. Comparing with similar studies degradation was likely by the meta cleavage pathway through cleavage of the meta-ring of 2,3 dihydroxy DDT [8]. Microorganisms employ oxygenases, dehalogenases, reductases, hydroxylases and dehydrogenases in degrading recalcitrant environmental compounds. Oxygenases which mainly take part in ring cleavage of aromatic compounds play a major role in the aerobic degradation process.

Aerobic degradation occurs by action of monoxygenases or dioxygenases depending on the number of oxygen atoms incorporated into the substrate to break up the ring [3]. Following the meta-cleavage pathway, DDT was degraded by double hydroxylation of the ring via formation of 2,3 Dihydrodiol DDT and subsequently 2,3 dihydroxy DDT, a yellow product and 4Chlorobenzoic acid as a stable metabolite [9, 19]. The proposed pathway is shown below in Figure 3. 


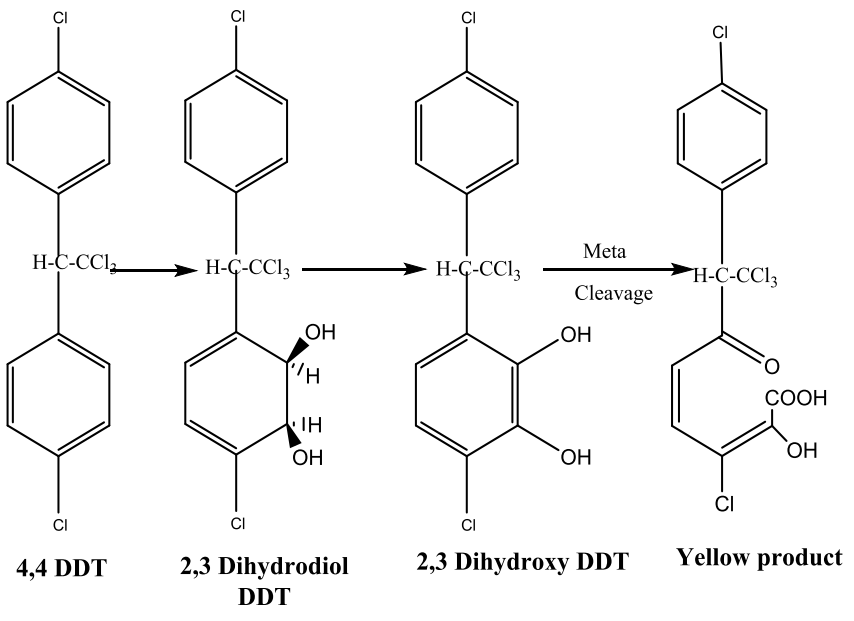

Fig. 3: Degradation of 4,4 DDT Following the Meta Cleavage Pathway [27].

Biphenyl-2,3-dioxygenase found in bacteria has been reported to be responsible for degrading diphenylmethane, diphenyl ether and diphenyl ethane which are related to DDT [17]. This suggests that the Rhodococcus sp. and Bacillus sp. Isolated possess the DDT-2,3-dioxygenase which allowed them to degrade 4,4 DDT via meta ring cleavage to yield a yellow product. Stearic hindrance exhibited by halogenated compounds such as 4,4 DDT and the resonance withdrawing effect of the chlorine atoms on the benzene ring may interfere with the enzymatic breakdown of 4,4 DDT making it difficult for some microbes to degrade some halogenated compounds [28]. The resonance withdrawing effect mainly affects the ortho- and para- positions leaving the meta position as the most reactive hence the degradation of 4,4 DDT following the meta cleavage pathway. This could have contributed to the failure by isolates 1,2, 4 and 6 to degrade 4,4 DDT in this study. Other studies have however suggested biodegradation of DDT by bacteria via co-metabolism with other chemicals [7].

\subsection{Metabolites of 4,4 DDT degradation}

Isolate 5 exhibited $88.36 \%$ and Isolate 3 exhibited $85.22 \%$ degradation of 4,4 DDT. Both isolates generated 4,4 DDD and 4,4 DDE as metabolites (Fig. 5 and 6). In both assays the peak for 4,4 DDT was lower than that of 4,4 DDD and 4,4 DDE indicating that 4,4 DDT was being converted to 4,4 DDD and 4,4 DDE, with the highest peak at 4,4 DDE as the major metabolite.

The Rhodococcus and Bacillus isolates degraded 4,4 DDT to 4,4 DDE and 4,4 DDD. Degradation of 4,4 DDT to 4,4 DDD catalyzed by the DDT reductive dehalogenase enzyme occurs anaerobically and this could mean that there was development of anaerobic conditions in the system leading to this reaction [7, 9]. DDD is considered less toxic than its parent molecule DDT. Mitotane the positional isomer of DDD formed when one of the para-chlorines in DDD is switched to orthoposition is a very useful chemotherapeutic agent.

Aerobic conversion of 4,4 DDT to 4,4 DDE normally occurs with the aid of the DDT dehydrochlorinase enzyme by a dehydrohalogenation reaction. Aerobic degradation of 4,4 DDT was predominant in this study as shown by the peak for 4,4 DDE in the chromatograms in figure 4 ( $\mathrm{a}$ and $\mathrm{b}$ ). Thus both isolates potentially harbor the two enzyme needed for both the aerobic and anaerobic degradation of 4,4 DDT. Consequently both 4,4 DDE and 4,4 DDD can be further degraded to metabolites for the metacleavage pathway through formation of DDMU $[1,9]$.
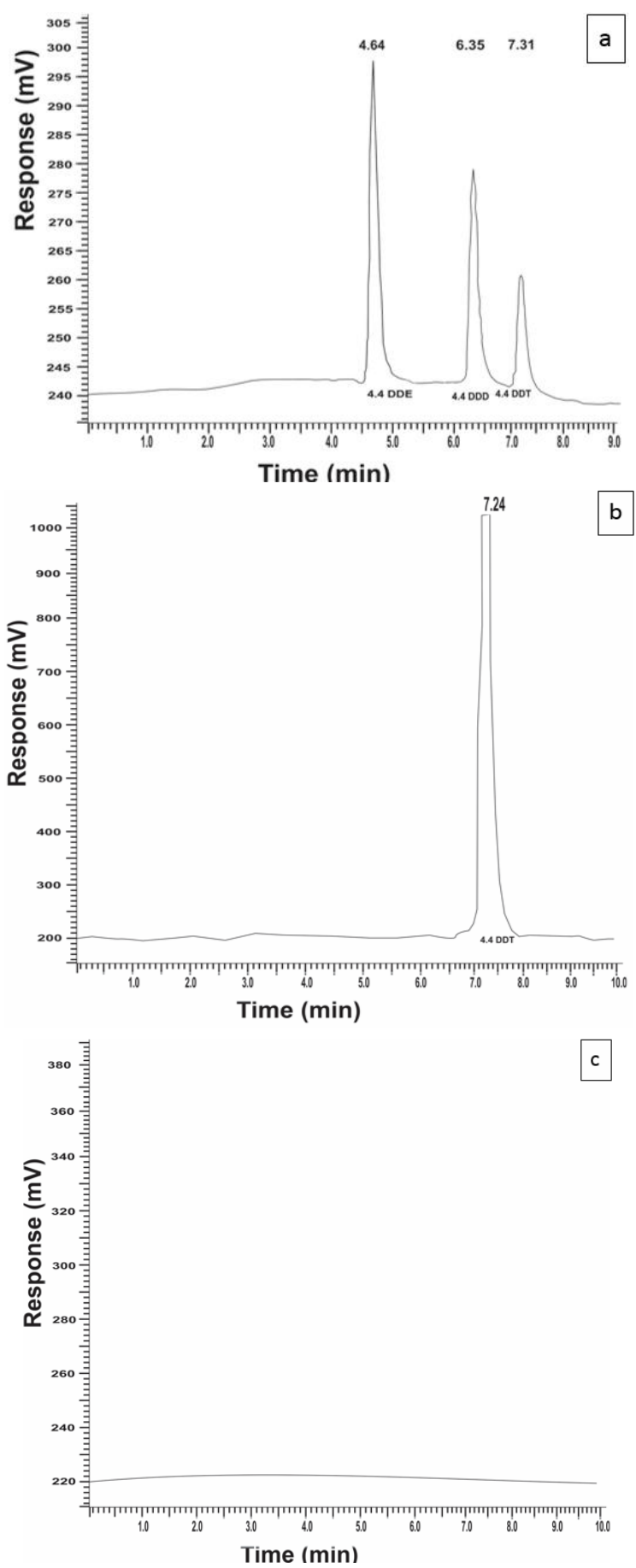

Fig. 4: The graphs show metabolites of biodegradation of 4,4 DDT detected using Gas Chromatography. The graphs show response $(\mathrm{mV})$ plotted against Time (minutes).(a) Chromatogram of 4,4 DDT degradation by Isolates 3 and 5 showing peaks at 4.64, 6.25 and 7.31 minutes for 4,4 DDE, 4,4 DDD and 4,4 DDT respectively (b)positive control for biodegradation of 4,4 DDT showing a peak at 7,24 minutes and (c)negative control for biodegradation of 4,4 DDT showing no peak for metabolites of 4,4 DDT. 


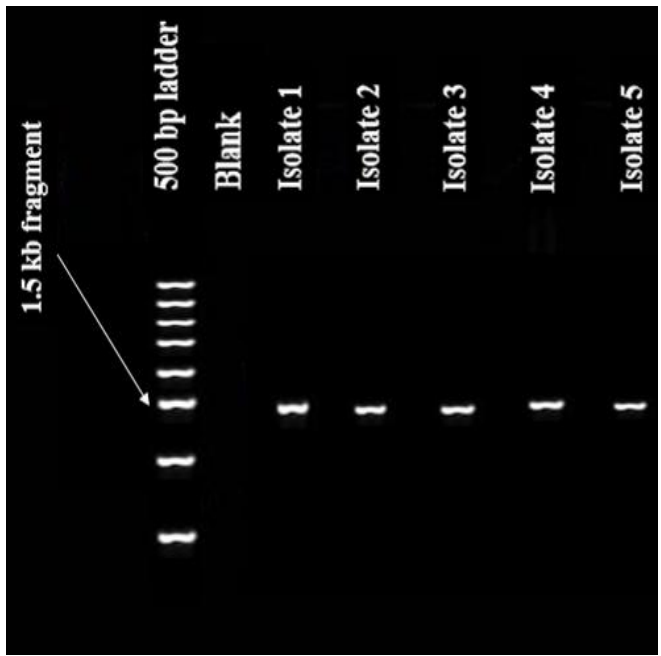

Fig. 5: 16S rRNA gene PCR amplicons on $1 \%$ agarose gel. DNA bands of about $1.5 \mathrm{~kb}$ were obtained from all the 5 isolates after 16S rRNA gene PCR. This shows that the conserved regions of the 16S rRNA gene were amplified by the $8 \mathrm{~F}$ and $1492 \mathrm{R}$ primer pair.

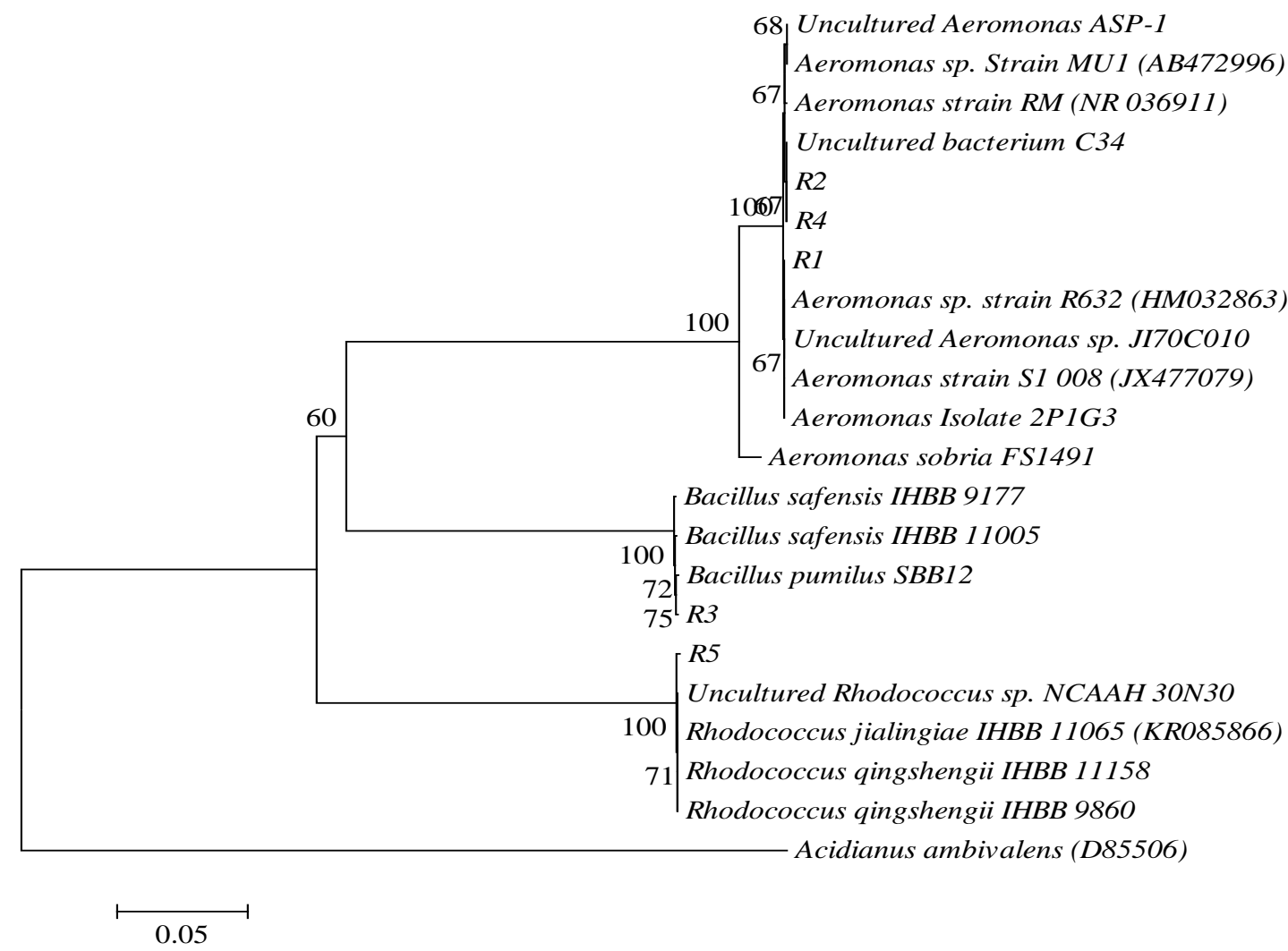

Fig. 6: Phylogenetic Tree Showing Positions of Isolates 1-6. The scale bar shows $1 \%$ sequence difference. The numbers at nodes show bootstrap values of each node out of 100 bootstrap resampling. The 16S rRNA gene sequence of Acidianus ambivalens D85506 was used as an outgroup.

\subsection{S rRNA gene analysis}

The 16S rRNA gene sequence analysis placed the isolates in the genera Aeromonas, Rhodococcus and Bacillus. BLAST search using the NCBI showed a similarity of $99 \%$ between isolates 1, 2 and 4 and Aeromonas sp. Isolate 3 showed a 99\% similarity with Bacillus sp. and Isolate 5 showed a $98 \%$ similarity with Rhodococcus sp.

Bacillus sp. are a member of the Gammaproteobacteria which tend to be tolerant to extreme physical and chemical conditions [29]. Therefore Bacillus sp. increase in abundance as they pass through the earthworm gut [26]. This is because they are able to withstand the harsh environment where competing microbes may express antibiotics or other inhibitory substances $[17,24]$. Consequently earthworm gut microbiota can be transitory in response to type of substrate media and or type of feed [24]. In the present study acclimatization to raw sewage was done to simulate conditions in a functional vermifilter that is used to treat sewage. Acclimatization also enhanced the effect of feed (sewage) on the micro biota inside the earthworm gut. Therefore the isolated microbes represent the actual microbes that can be found in the 
earthworms' guts during vermifiltration of sewage and hence the actual possibility of removing 4,4 DDT from sewage during vermifiltration processes.

The results provide part of the baseline data needed in optimization of sewage treatment vermifilters for removal of persistent and toxic chemicals such as DDT. This can be done by bio-augmenting the populations of xenobiotic degrading microbes and adjusting conditions in the sewage treatment process to favor their proliferation. Earthworms can also be used as biological vectors to transfer DDT-degrading microorganisms into a target contaminated environment for bioremediation. [8]. Earthworms through their burrowing action will transport the microbes in their drilosphere, effectively distributing them for efficient bioremediation without excavation of contaminated sites [16].

This study therefore highlights the ever-increasing potential applications of earthworms and their gut microflora as a tool for biodegradation and bioremediation of persistent compounds in the environment. It is however pertinent that mineralization of 4,4 DDT is ensured and established in bioremediation efforts since some metabolites of 4,4 DDT such as 4,4 DDE and 4,4 DDD are toxic to humans and the environment. Degradation of 4,4 DDT as a sole source of carbon yields its toxic metabolites such as DDE and DDD. This is because without an additional substrate to derive energy from microorganisms only cause modest changes on the DDT molecule.

\section{CONCLUSION}

The gut of E. fetida acclimatized to sewage hosts bacteria of the Rhodococcus and Bacillus genera that have the potential to degrade 4,4 DDT. It follows that in a vermifiltration-based bioreactor the sewage treatment process can be optimized to increase removal of persistent chemicals such as DDT. Further studies can be done to characterize co-metabolism of 4,4 DDT, to possibly achieve more complete degradation of the compound.

\section{ACKNOWLEDGEMENTS}

Financial support and sponsorship: We acknowledge the research grant from Chinhoyi University of Technology Senate Research Committee (SERC).

Conflict of Interests: There are no conflicts of interest.

\section{REFERENCES}

1. Foght J, April T, Biggar K, Aislabie J. Bioremediation of DDTcontaminated soils: a review. Bioremediation Journal. 2010; 5. 225-246.

2. Moser R, Stahl U. Insights into the genetic diversity of initial dioxygenases from PAH-degrading bacteria. Applied Microbiology and Biotechnology. 2000; 55. 609-618.

3. Arora PK, Srivastava A, Singh VP. Application of monooxygenases in dehalogenation, desulphurization, denitrification and hydroxylation of aromatic compounds. Journal Bioremediation and Biodegradation. 2010; 1:112.

4. Chigu NL, Hirosue S, Nakamura C, Teramoto H, Ichinose H, Wariishi $\mathrm{H}$. Cytochrome P450 monooxygenases involved in anthracene metabolism by white-rot basidiomycete Phanerochaete chrysosporium. Applied Microbiology and Biotechnology. 2010; 87. 1907-1916.

5. Siripong P, Oraphin B, Sanro T, Duanporn P. Screening of Fungi from Natural Sources in Thailand for Degradation of Polychlorinated Hydrocarbons. Am-Euras. Journal of Agricultural and Environmental Science. 2009; 5(4): 466-472.

6. Dhaliwal GS, Arora R. Role of Phytochemicals in Integrated Pest Management. In: Koul O, Dhaliwal GS (eds) Phytochemical Biopesticides. Overseas Publishers Association by license under the Harwood Academic Publishers, Netherlands; 2001; 87-106.

7. Aislabie JM, Richards NK, Boul HL. Microbial degradation of DDT and its residues-A review. New Zealand Journal of Agricultural Research. 2010; 40(2): 269-282.

8. Chandrappa M, Kamanavalli, Harichandra Z, Ninnekar. Biodegradation of DDT by a Pseudomonas Species. Current Microbiology. 2003; 48. $10-13$.

9. Mwangi K, Boga IH, Muigai WA, Kiiyukia C, Tsanuo KM. Degradation of dichlorodiphenyltrichloroethane (DDT) by bacterial isolates from cultivated and uncultivated soil. African Journal of Microbiology Research. 2010; 4(3): 185-196.

10. World Health Organization. Lindane in Drinking-water. 2004. (WHO/SDE/WSH/03.04/102)Available: http://www.who.int/water_sanitation_health/dwq/chemicals/lindane.pdf.

11. Badawy MI, Ali MEM. Removal of some of priority organic pollutants (POPs) in conventionally treated wastewater. AfinidAd LXVii. 2010; 547.

12. Sinha RK, Heart S, Valani D. Earthwormsthe environmental engineers: a review of vermiculture technologies for environmental management and resource development. International Journal of Global Environmental Issues. 2010; 10. 265-292.

13. Xia C, Ma X, Liu S, Fan P. Studies on remediation of DDTcontaminated soil and dechlorination of DDT. Procedia Environmental Science. 2012; 16. 289-292.

14. Singh PK, Mohan D, Sinha S, Dalwani R. Impact assessment of treated/untreated wastewater toxicants discharged by sewage treatment plants on health, agricultural, and environmental quality in the wastewater disposal area. Chemosphere. 2003; 55. 227-255.

15. Siripong P, Oraphin B, Sanro T, Duanporn P. Screening of Fungi from Natural Sources in Thailand for Degradation of Polychlorinated Hydrocarbons. Am-Euras. Journal of Agriculture and Environmental Science. 2009; 5(4): 466-472.

16. Kim H, Shin K, Cha C, Hur H. Analysis of aerobic and culturable bacterial community structures in earthworm (Eisenia fetida) intestine. Agriculture, Chemistry and Biotechnology. 2004; 47(3): 137-142.

17. Kimura N, Kato H, Nishi A, Furakawa K. Analysis of substrate range of biphenyl-catabolic enzymes. Bioscience, Biotechnology and Biochemistry. 1996; 60. 220-223.

18. Songkong K, Prasertsan P, Sobhon V. Screening and identification of p,p'-DDT degrading soil isolates. Songklanakarin Journal of Science and Technology. 2008; 30(1): 103-110.

19. Nadeau LJ, Menn FM, Breen A, Sayler GS. Aerobic degradation of 1,1,1-Trichloro-2,2-bis(4- chlorophenyl)ethane (DDT) by Alcaligenes eutrophus A5. Applied Environmental Microbiology. 1994; 60:1. 51-55.

20. Nadeau LJ, Sayler GS, Spain JC. Oxidation of 1,1,1-trichloro-2,2-bis(4hlorophenyl)ethane(DDT) by Alcaligenes eutrophus A5. Archives of Microbiology. 1998; 171. 44-49.

21. Soto MA, Toha J. Ecological wastewater treatment; Advanced wastewater treatment, recycling and reuse; AWT 98. 1998. Milano, 1416 September 2008.

22. Parthasarathi K, Ranganathan LS. Profiles of enzyme activity in the gut of Lampito mauritii and Eudrilus euginiae reared on various substrates. Journal of Tropical Ecology. 2000; 41(2): 251-254.

23. Manyuchi M, Phiri A. Bioremediation of transport industry contaminants using vermicompost. International Journal of Environmental Engineering Science and Technology. 2014; 2(1): 1-7.

24. Gómez-Brandón M, Aira M, Lores M, Domínguez J. Epigeic earthworms exert a bottleneck effect on microbial communities through gut associated processes. PLoS ONE. 2011; 6(9). 
25. Barragan-Huerta BE, Costa-Perez C, Peralta-Cruz J, Barrera-Cortes J, Esparza-Garcia F, Rodriguez-Vazquez R. Biodegradation of organochlorine pesticides by bacteria grown in microniches of the porous structure of green bean coffee. 1st International Conference on Environmental, Industrial and Applied Microbiology. International Biodeterioration and Biodegradation. 2007; 59(3): 239-244.

26. Pant G, Mistry SK, Sibi G. Isolation, Identification and Characterization of p, p'-DDT Degrading Bacteria from Soil. Journal of Environmental Science and Technology.2013; 61. 130-137.

27. Houghton JE, Shanley SM. Catabolic potential of Pseudomonads: a regulatory perspective. Biological degradationand bioremediation of toxic chemicals, Dioscorides press, Portland. 1994; 11-32.

28. Banta G, Kahlon RS. Dehalogenation of 4-Chlorobenzoic acid by Pseudomonas isolates. Indian Journal of Microbiology. 2007; 47. 139143.

29. Broszat M, Nacke H, Blasi R, Siebe C, Huebner J, Daniel R, Grohmann E. Wastewater irrigation increases the abundance of potentially harmful gammaproteobacteria in soils in Mezquital valley, Mexico. Applied Environmental Microbiology. 2014; 80(17): 5282-5291.

\section{How to cite this article:}

Mudziwapasi R, Mlambo SS, Chigu NL, Kuipa PK, Sanyika WT. Isolation and molecular characterization of bacteriafrom the gut of Eisenia fetida for biodegradation of 4,4 DDT. J App Biol Biotech. 2016; 4 (05): 041-047. DOI: 10.7324/JABB.2016.40507 